\title{
OPTIMAL LOCATING-TOTAL DOMINATING SETS IN STRIPS OF HEIGHT 3
}

\author{
Ville JunNilA ${ }^{1}$ \\ Department of Mathematics and Statistics \\ University of Turku, FI-20014 Turku, Finland \\ e-mail: viljun@utu.fi
}

\begin{abstract}
A set $C$ of vertices in a graph $G=(V, E)$ is total dominating in $G$ if all vertices of $V$ are adjacent to a vertex of $C$. Furthermore, if a total dominating set $C$ in $G$ has the additional property that for any distinct vertices $u, v \in V \backslash C$ the subsets formed by the vertices of $C$ respectively adjacent to $u$ and $v$ are different, then we say that $C$ is a locating-total dominating set in $G$.

Previously, locating-total dominating sets in strips have been studied by Henning and Jafari Rad (2012). In particular, they have determined the sizes of the smallest locating-total dominating sets in the finite strips of height 2 for all lengths. Moreover, they state as open question the analogous problem for the strips of height 3. In this paper, we answer the proposed question by determining the smallest sizes of locating-total dominating sets in the finite strips of height 3 as well as the smallest density in the infinite strip of height 3 .
\end{abstract}

Keywords: locating-total dominating set, domination, square grid, strip.

2010 Mathematics Subject Classification: 05C70, 68R05, 94B65, 94C12.

\section{REFERENCES}

[1] M. Blidia, M. Chellali, F. Maffray, J. Moncel and A. Semri, Locating-domination and identifying codes in trees, Australas. J. Combin. 39 (2007) 219-232.

[2] M. Blidia and W. Dali, A characterization of locating-total domination edge critical graphs, Discuss. Math. Graph Theory 31 (2011) 197-202. doi:10.7151/dmgt.1538

\footnotetext{
${ }^{1}$ Research supported by the Väisälä Foundation of the Finnish Academy of Science and Letters, and the Finnish Cultural Foundation.
} 
[3] M. Blidia, O. Favaron and R. Lounes, Locating-domination, 2-domination and independence in trees, Australas. J. Combin. 42 (2008) 309-316.

[4] M. Bouznif, Algorithmes génériques en temps constant pour la résolution de problèmes combinatoires dans la classe des rotagraphes et fasciagraphes. Application aux codes identifiants, dominants-localisateurs et dominants-total-localisateurs, Ph.D. Dissertation, Grenoble University (2012).

[5] M. Bouznif, J. Moncel and M. Preissmann, Generic algorithms for some decision problems on fasciagraphs and rotagraphs, Discrete Math. 312 (2012) 2707-2719. doi:10.1016/j.disc.2012.02.013

[6] X.-G. Chen and M.Y. Sohn, Bounds on the locating-total domination number of a tree, Discrete Appl. Math. 159 (2011) 769-773.

doi:10.1016/j.dam.2010.12.025

[7] T.W. Haynes, M.A. Henning and J. Howard, Locating and total dominating sets in trees, Discrete Appl. Math. 154 (2006) 1293-1300.

doi:10.1016/j.dam.2006.01.002

[8] M.A. Henning and N. Jafari Rad, Locating-total domination in graphs, Discrete Appl. Math. 160 (2012) 1986-1993.

doi:10.1016/j.dam.2012.04.004

[9] P.J. Slater, Fault-tolerant locating-dominating sets, Discrete Math. 249 (2002) 179189.

doi:10.1016/S0012-365X(01)00244-8

Received 4 December 2013

Revised 1 September 2014

Accepted 1 September 2014 